\title{
A new tardigrade species of the genus Neostygarctus Grimaldi de Zio et al., 1982 (Tardigrada, Arthrotardigrada) from the Great Meteor Seamount, Northeast Atlantic
}

\author{
Alexei V. TCHESUNOV \\ Department of Invertebrate Zoology, Faculty of Biology, M.V. \\ Lomonosov Moscow State University, Moscow, 119991, Russia \\ Email:AVTchesunov@yandex.ru
}

urn:1sid:zoobank.org:author:DFCA40C7-F642-4BD0-AC96-1E24162C2305

\begin{abstract}
A new species of Neostygarctus Grimaldi de Zio et al., 1982 is described from the Great Meteor Seamount summit plateau in the Northeast Atlantic. Neostygarctus grossmeteori sp. nov. is characterized by the number and position of dorsomedian spines (five spines on the cephalic plate and each body plate and on the caudal plate, the spines decreasing in length backwards); the presence of eyes and of one or two pairs of ventral cervical spines; a transversal row of two to five short but strong spikes on the ventral side of the lateral body processes; only the internal claws of each leg provided with a normal accessory spine. The new species is related to N. acanthophorus Grimaldi de Zio et al., 1982 but differs by details of the dorsal body spines and the sculptures, the presence of ventral neck spines and ventral spikes on lateral body projections. Neostygarctus grossmeteori sp. nov. differs from two other known species of Neostygarctus, N. oceanopolis Kristensen et al., 2015 (Condor Seamont, NE Atlantic) and N. lovedeluxe Fujimoto \& Miyazaki, 2013 (submarine cave NW Pacific), even more obviously by the number and position of dorsal body spines.
\end{abstract}

Keywords. Arthrotardigrada, marine Tardigrada, Neostygarctus, seamounts, taxonomy.

Tchesunov A.V. 2018. A new tardigrade species of the genus Neostygarctus Grimaldi de Zio et al., 1982 (Tardigrada, Arthrotardigrada) from the Great Meteor Seamount, Northeast Atlantic. European Journal of Taxonomy 479: 1-17. https://doi.org/10.5852/ejt.2018.479

\section{Introduction}

The phylum Tardigrada Doyère, 1840 comprises two main classes, namely Eutardigrada Richters, 1926 and Heterotardigrada Marcus, 1927. The latter class is distinguished from the largely limnetic and terrestrial Eutardigrada by the presence of separate anal and genital openings as well as by setose and papillose sensory head and body appendages. Heterotardigrada is in turn subdivided into two orders, Echiniscoidea Richters, 1926, a mainly moss-dwelling taxon but with a few marine species, and the almost purely marine Arthrotardigrada Marcus, 1927 characterized by the presence of a median cirrus on the head, often telescoping legs and digits with claws and/or suction discs. Marine arthrotardigrades 
comprise currently over 190 species and subspecies and thus represent about $15 \%$ of all tardigrade taxa (Degma et al. 2017; Fontoura et al. 2017). Marine arthrotardigrades are known worldwide but they remain rarely seen and poorly studied organisms with an obscure biology. They are mostly smaller than their moss-dwelling and freshwater relatives, often need some special and time-consuming techniques for extraction and observation; and furthermore, collection of marine species especially those from deeper zones, is technically hard and costly. Therefore, their actual diversity may be underestimated. Bartels et al. (2016) mention a low taxonomic effort for describing marine tardigrades and predict their actual diversity could be close to 1000 species thus approaching or even exceeding the number of the more thoroughly studied limnoterrestrial tardigrades. Despite a lower species diversity, the marine arthrotardigrades show a higher morphological diversity or even disparity across taxa that is expressed in greater numbers of higher taxa per species. Thus, the ratio in numbers of families, genera and species in Arthrotardigrada is 1:7.5:11.9 whereas the same in Echiniscoidea is 1:4:73.5 and in Eutardigrada 1:3.8:66.2, respectively (data from Degma et al. 2017). Genera of arthrotardigrades differ from one another in the number and shape of digits, head and body sensory appendages and body sculptures, while the genera within Echiniscoidea and Eutardigrada are morphologically more uniform.

Arthrotardigrades occur in all oceans and in nearly all ocean depth zones from even above sea level in the sand saturated by seawater to the abyssal plains, and in all substrates including sands, silts and fouling. However, a higher diversity is registered in medium to coarse sediments, especially in carbonate sands deposited in shallow environments (e.g., Renaud-Mornant 1988; Giere 2009). The tardigrade fauna of seamounts attracts a special interest because of its richness and peculiarity. Seamounts and ocean banks present isolated habitats, remote from continental coastlines, but with conditions similar to those of the nearshore zone, i.e., shallow depths, with strong near bottom currents and coarse-grained bottom sediments. Hansen et al. (2001) and Hansen (2005) discovered 35 tardigrade species on the Faroe Bank in the NE Atlantic Ocean. Other findings of seamount tardigrades were made also in the same region (Jørgensen \& Kristensen 2001; Hansen et al. 2003) or in other regions of the NE Atlantic (Kristensen et al. 2015).

The summit plateau of the Great Meteor Seamount (GMS) constitutes a quite peculiar isolated biotope, populated by meiofauna with a high percentage of endemism (see, e.g., George \& Schminke 2002; Gad 2002, 2004a, 2004b, 2009; George 2006, 2013). GMS is located in the subtropical North-East Atlantic Ocean, about $1340 \mathrm{~km}$ west of the nearest mainland of Africa and over $750 \mathrm{~km}$ south of the Azores (Fig. 1A). GMS is a giant tablemount or 'guyot' of volcanic origin. It rises up from a depth of 4200 to about $270 \mathrm{~m}$ below the sea surface. The giant summit plateau is an oval $50 \mathrm{~km} \times 28 \mathrm{~km}$ in size or $1500 \mathrm{~km}^{2}$ in area. The plateau is covered by well-sorted carbonate bioclastic sands consisting mainly of dead planctonic shells of foraminiferans and pteropod gastropods derived from the water column (Fig. 1B). An additional component of the sediment are relict carbonate grains derived from reworked bioclastic limestones (Mohn 2010).

The aim of the present paper is the description of a new tardigrade species inhabiting the summit plateau of the Great Meteor Seamount.

\section{Material and methods}

The meiofauna on the Great Meteor Seamount plateau was sampled during the Expedition P397 GroMet of the RV Poseidon in March 2010. The samples were taken with a Van Veen-grab and yielded a rich fauna of meiobenthic organisms. Immediately on board, the sediment sample was washed and sieved through a $40 \mu \mathrm{m}$ mesh size. The sieved material was fixed with $4 \%$ buffered formalin. Subsequently, the material was centrifugated three times for each 5 minutes at $4000 \mathrm{rpm}$, using Levasil as floating medium in the laboratories of the German Centre for Marine Biodiversity Research (GCMBR, Senckenberg am 
Meer, Wilhelmshaven, Germany). Afterwards, the material was sorted and tardigrades were picked out under a Leica stereo microscope.

At the GCMBR, the tardigrades were preserved in glycerin. I received the material as specimens already mounted in temporary glycerin slides. The specimens were then remounted in permanent glycerin slides, sealed with a paraffin-beewax ring and with glass beads as a separator between the cover slip and the glass slide. The specimens were observed, measured, drawn and illustrated under a light microscope Leica DM 5000. Two specimens were examined by scanning electron microscopy (SEM). These were de-mounted from the glycerin slides, slowly transferred from the glycerin to water and then via increasing ethanol solutions to aceton, critical point dried, coated with a platinum-palladium alloy and examined under a Cam Scan S-2.

Initial fixation with formalin makes extraction of DNA and further molecular analysis impossible. Internal organs of nearly all the specimens examined are macerated at various degree; some specimens look quite transparent having only remnants of the pharyngeal bulb and midgut.

Terminology for the description is generally adopted from Kristensen et al. (2015) and Fontoura et al. (2017).

All measurements are in $\mu \mathrm{m}$, and all curved structures are measured along the arc. All numbers of spines on head lobes, lateral body processes, wart-like lobes on body, and on legs IV are referred to the holotype.

\section{Abbreviations in the text and on figures are as follows}
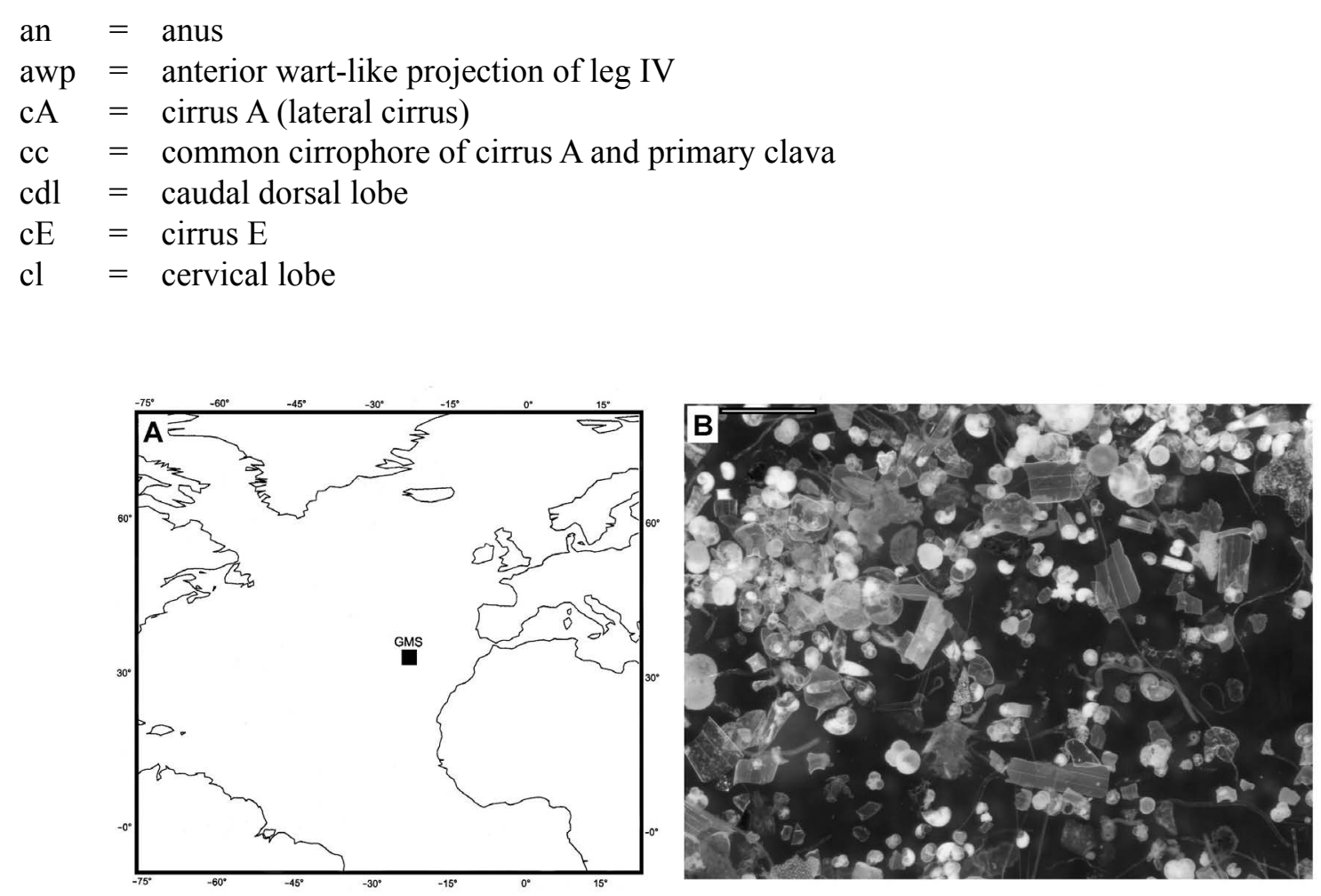

Fig. 1. Type locality and milieu of Neosstygarctus grossmeteori sp. nov. A. Position of the Great Meteor Seamount in the Atlantic Ocean. B. Bioclastic sediment consisting mainly of calcareous foraminiferan and pteropod shells (fine fraction of sediment washed off). Scale bar $=2 \mathrm{~mm}$. 


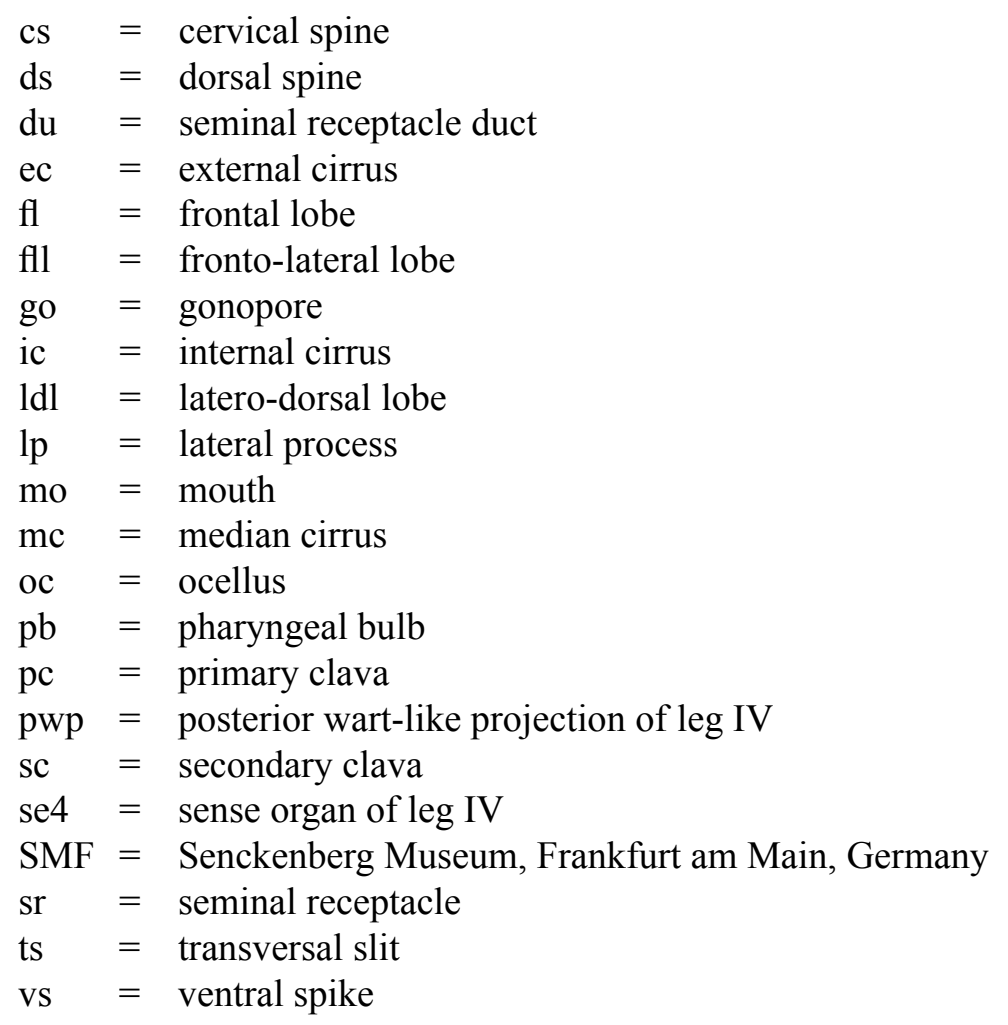

\section{Results}

Phylum Tardigrada Doyère, 1840

Class Heterotardigrada Marcus, 1927

Order Arthrotardigrada Marcus, 1927

Family Stygarctidae Schulz, 1951

Subfamily Stygarctinae Schulz, 1951

Genus Neostygarctus Grimaldi de Zio, D’Addabbo Gallo \& Morone de Lucia, 1982

\section{Type species}

Neostygarctus acanthophorus Grimaldi de Zio, D’Addabbo Gallo \& Morone de Lucia, 1982

Diagnosis (after Kristensen et al. 2015 and Fontoura et al. 2017, modified)

Stygarctinae with five dorsal plates bearing dorsal spines and always three pairs of lateral trunk processes with cuticular spines. Cuticular spines also present on the head, body, and on the fourth leg pair. Up to five very thin ventral plates sometime seen as folds only. Cephalic region subdivided into six lobes; anterior frontal pair with two ventral internal cirri and a large dorsal median cirrus present near the base of the frontal lobe; fronto-lateral pair with ventral external cirri and secondary clavae; the lateral lobes consist of very long common cirrophores for lateral cirri and primary clavae. All six lobes have cuticular spines; furthermore, two swollen lobe with spines are present dorsal and posterior on the cephalic plate, and similar lateral swollen with spines are present on the caudal plate. Cirrus E very large with accordion-like articulation. Sense organs on fourth leg pair, similar to primary clava. Legs with four digits, each with a dorsal cuticular support ending in a triangular, solid claw. All four claws with or without dorsal bristle. Stylet supports absent. Oval male gonopore situated close to lobed anus. Female gonopore formed as a six-lobed, midventral rosette on the caudal region; two seminal receptacles present, located caudal to the female gonopore, and with sinuous duct openings as two cuticular tubes lateral to the gonopore. 


\section{Neostygarctus grossmeteori sp. nov. urn:1sid:zoobank.org:act:0047D8B7-BEAE-4751-B098-86EA728FABA3}

Figs 2-6, Table 1 (morphometrics)

\section{Diagnosis}

Neostygarctus with five middorsal spines on the cephalic and each body plate and on the caudal plate, the spines decreasing in length backwards. Ocelli present. One or two pairs of ventral cervical spines present. Each lateral body process provided basally on the ventral side with a transversal row of two to five short but strong spikes. Only inner claws of each foot provided with a fine dorsal accessory spine; external claws may carry vestigial accessory spines.

\section{Etymology}

The species name is derived from the name of locality (Gross Meteor in German).

\section{Type material}

\section{Holotype}

ATLANTIC OCEAN: + , Great Meteor Seamount plateau, $29^{\circ} 48.974$ N, $28^{\circ} 25.941 \mathrm{~W}$, depth $299 \mathrm{~m}$, RV Poseidon, expedition P397 GROMET, location \#17, stn 106-6, 1 Mar. 2010 (SMF 51).

\section{Paratypes}

ATLANTIC OCEAN: 3 우 (SMF 52-54), 1 (SMF 58), one specimen of unidentified gender (SMF 60) (Table 1), same data as for the holotype. The holotype and the paratypes are all embedded in permanent glycerin slides.

\section{General description}

Body SURFACE AND SCULPTURES. Dorsal cuticle consists of five transversal dorsal plates (one cephalic, three body and one caudal plates) and intermediate areas between them (Fig. 2A). Ventral cuticular plates not developed as such; the only transversal cuticular folds may be discernible (Fig. 2B). Edges of dorsal plates discernible as discontinuous cuticular folds which may be obscured here and there. Cuticle of plates hardly differs from that of intermediate areas - but sparse and irregular coarse punctuations on dorsal plates (Fig. 2A), which are, in fact, seemingly epicuticular pillars not detectable in SEM on surface but visible in optical microscope laterally as short projecting bars. Five robust middorsal spines present, which are elongated and conical, with acute or slightly rounded tips. Each plate carries one median spine attached in pit in middle on cephalic and on body plates I and II, close to posterior edge on body plate III, and close to anterior edge of caudal plate. Middorsal spines tend to be reducing in length from cephalic to caudal plate (Fig. 2A, ds). Set of middorsal spines may be incomplete in some specimens (Table 1), possibly because of loss.

Cephalic region (Figs 2A-B, 3A-B). Anteriorly subdivided into two pairs of lobes densely feathered by fine hollow cuticular spines: two frontal semicircular lobes (fl), two fronto-lateral lobes (fll), also semicircular but less prominent, and two long lateral common cirrophores of cirrus A and primary clava (cc). Pair of not very prominent but distinct latero-dorsal wart-like cervical lobes (cl) on narrowed neck region just posterior to lateral cirrophores. Dorsal cuticle of cephalic region marked by sparse and irregularly distributed coarse punctuations which are actually projections of short rod-like epicuticular pillars (Fig. 3A). Long middorsal spine at level of cervical lobes. Anterior edges of frontal and frontolateral lobes as well as both anterior and posterior edges of lateral cirrophores on head flanked by tight rows of finest hollow spines: about 15 spines on frontal lobe, 10-12 spines on fronto-lateral lobe, 9-11 spines on anterior and about 15 spines on posterior edge of lateral lobe. Spines of anterior frontal lobes very fine, spines of fronto-lateral lobes and then to anterior and posterior edges of body lateral processes 
Table 1. Measurements (in $\mu \mathrm{m}$ ) of Neostygarctus grossmeteori sp. nov.

\begin{tabular}{|c|c|c|c|c|c|c|}
\hline \multirow{2}{*}{$\begin{array}{l}\text { Character } \\
\text { Inventory number }\end{array}$} & \multicolumn{4}{|c|}{$\begin{array}{l}\text { Holotype female (51) } \\
\text { and paratype females }(52-54)\end{array}$} & \multirow{2}{*}{$\begin{array}{c}\begin{array}{c}\text { Paratype } \\
\text { male }\end{array} \\
\text { SMF } 58\end{array}$} & \multirow{2}{*}{$\begin{array}{c}\begin{array}{c}\text { Paratype } \\
\text { of obscure } \\
\text { gender }\end{array} \\
\text { SMF } 60\end{array}$} \\
\hline & SMF 51 & SMF 52 & SMF 53 & SMF 54 & & \\
\hline Body length & 167 & 181 & 195 & 177 & 166 & 161 \\
\hline Median cirrus & 42 & 57 & 67 & 45 & 63 & 39 \\
\hline Internal cirrus & 26 & 29 & 18 & 23 & 25 & 17.5 \\
\hline External cirrus & 47 & 50 & 54 & 47 & 43 & 45 \\
\hline Cirrus A & 62 & 54 & 61 & 65 & 62 & 50 \\
\hline Primary clava & 6.5 & 6 & 7 & 5.4 & 7 & 6 \\
\hline $\begin{array}{l}\text { Secondary clava } \\
\text { length } \times \text { width }\end{array}$ & $7.5 \times 7$ & $8 \times 7$ & $6.5 \times 9$ & $5.6 \times 7.3$ & $6.5 \times 7.6$ & $6 \times 7$ \\
\hline Dorsal spine I & 42 & $?$ & 67 & $\begin{array}{l}\text { missing } \\
\text { (lost?) }\end{array}$ & 64 & 48 \\
\hline Dorsal spine II & 26 & 44 & 20 & $\begin{array}{l}\text { missing } \\
\text { (lost?) }\end{array}$ & missing (lost?) & 47 \\
\hline Dorsal spine III & 31 & 39 & 18 & $\begin{array}{l}\text { missing } \\
\text { (lost?) }\end{array}$ & 29 & 46 \\
\hline Dorsal spine IV & 16 & 29 & 16 & $\begin{array}{l}\text { missing } \\
\text { (lost?) }\end{array}$ & 18 & 27 \\
\hline Dorsal spine V & 6 & 9 & 6 & $\begin{array}{l}\text { missing } \\
\text { (lost?) }\end{array}$ & 2 & 3 \\
\hline Cirrus E & 112 & 113 & 129 & 97 & 121 & 118 \\
\hline Leg IV sense organ & 5.9 & 5.8 & 6.7 & 5.1 & 5.6 & 3.8 \\
\hline Leg I digits & 21 & 22 & 17 & 18 & 20 & 16 \\
\hline Leg IV digits & 26 & 25 & 26 & 26 & 24 & 23 \\
\hline
\end{tabular}

become gradually more and more robust. Cervical lobes bear about eight medium-sized, slightly curved spines each. Fine spines arranged in tight rows on all head and body processes joined with thin film or membrane (Fig. 2A-B); rags of the membranes observable in SEM (Fig. 6E). About two pairs of straight medium-sized ventro-lateral cervical spines (cs) on neck region just posterior to cervical lobes. Anterior cervical spines a bit smaller and located more antero-ventrally than posterior cervical spines (the latters are paired on either side in one specimen). Soft mouth cone on ventral side situated a bit posterior to anterior head edge.

BoDy SEGMENTS I-III. With long lateral processes (lp) almost normal to long body axis, ornamented by rows of long hollow spines on anterior and posterior edges; terminal narrowed region of processes lack spines and slightly curved rearward (Figs 2A-B, 4E, 5A, 6A-B, D). Spines make processes feather-like. Numbers and position of spines on body lateral projections: (1) about 10 medium-sized spines arranged in arch dorso-posteriorly near bases of processes; (2) about 19-22 long marginal spines along anterior edge of process; (3) about 14-16 also long marginal spines along posterior edge of process (both anterior and posterior rows of marginal sets of dorso-lateral process give impression of feather). Two to five short and stout but acute ventral conical spikes (vs) arranged in row parallel to long body axis on ventral side of each lateral body process (Figs 2B, 5A, 6C). Pair of wart-like latero-dorsal lobes (ldl) on each body segment just posterior to long lateral processes on segments I-III and in the middle on caudal segment. 


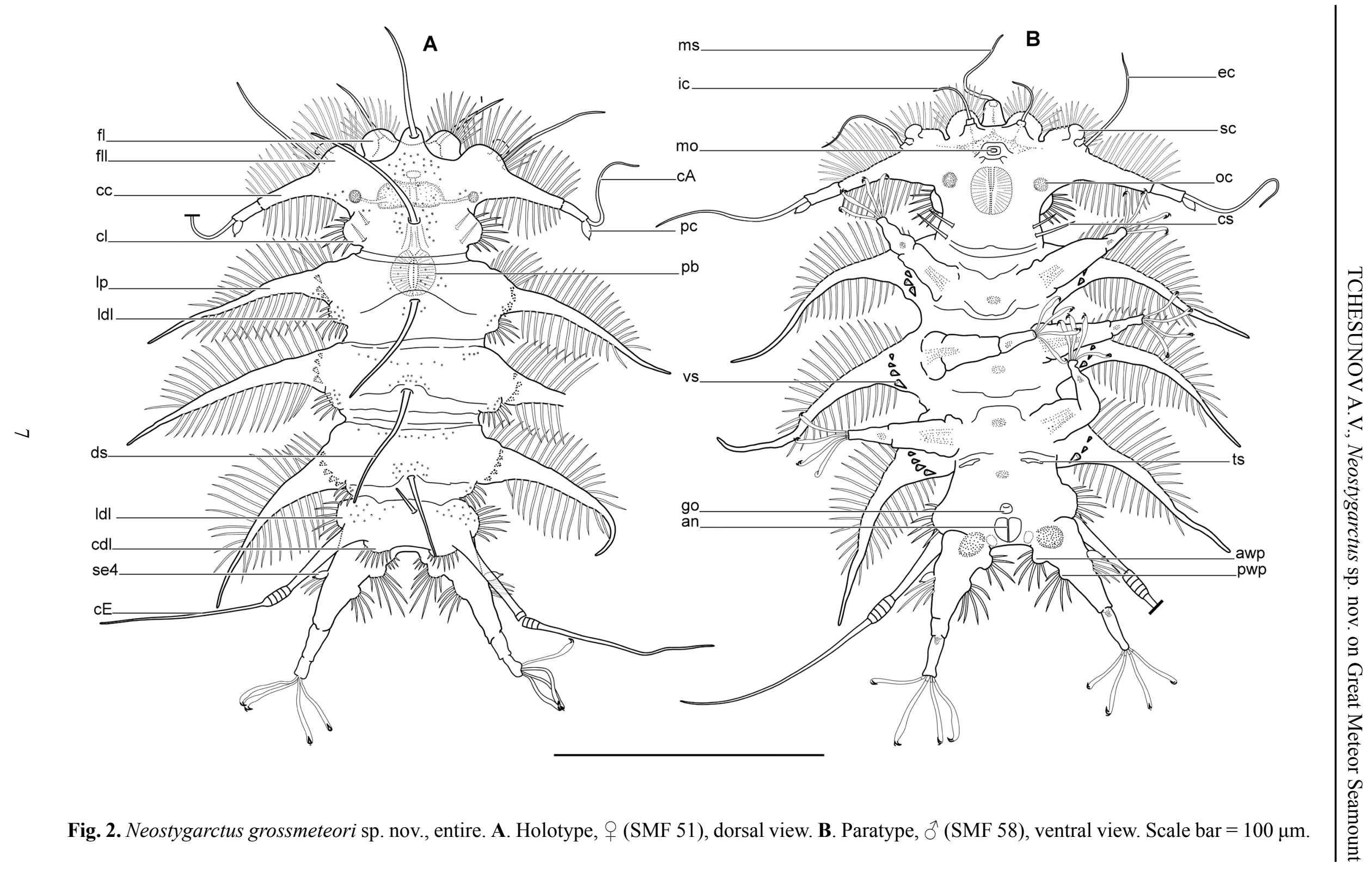




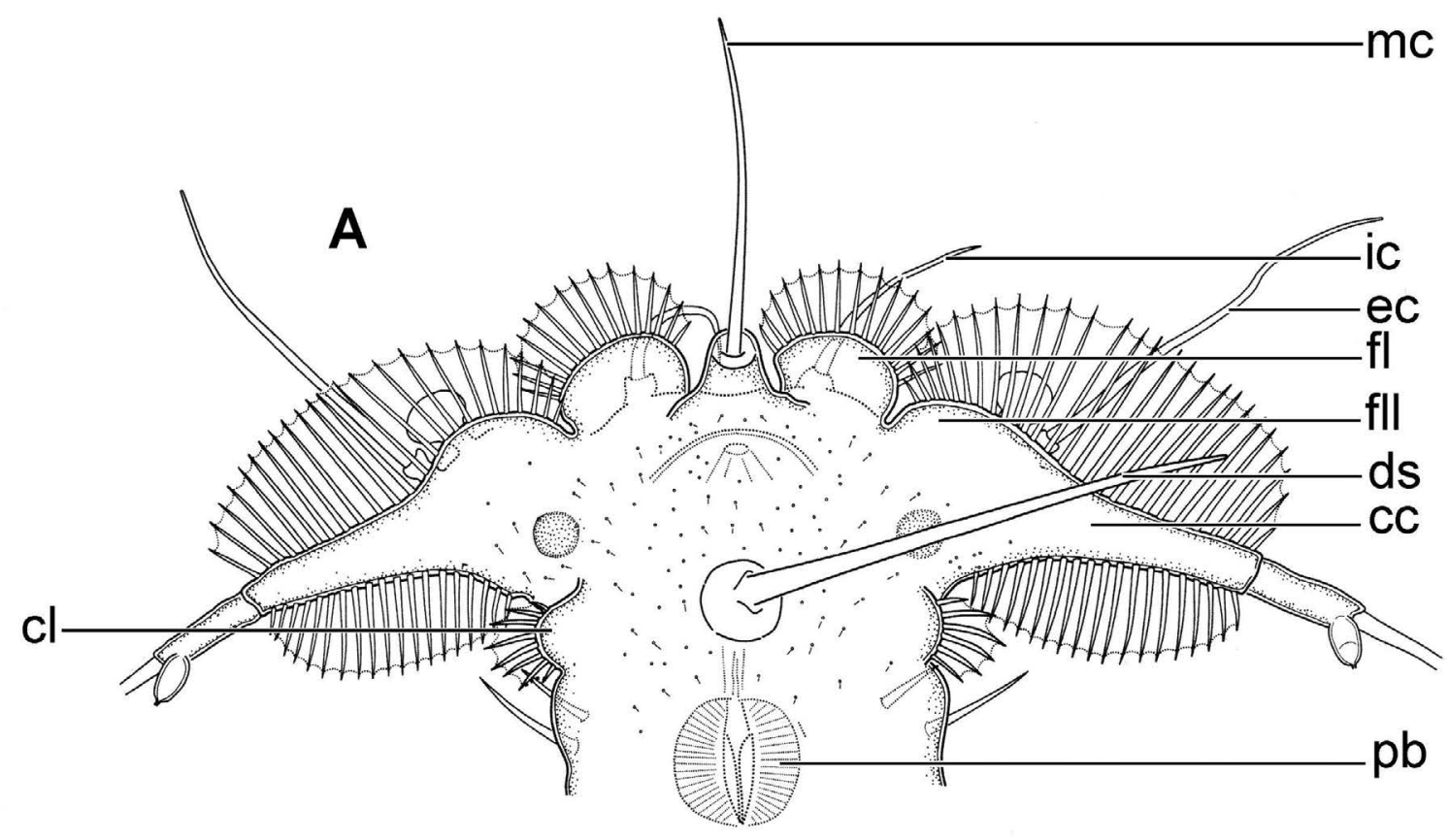

mc

\section{b}

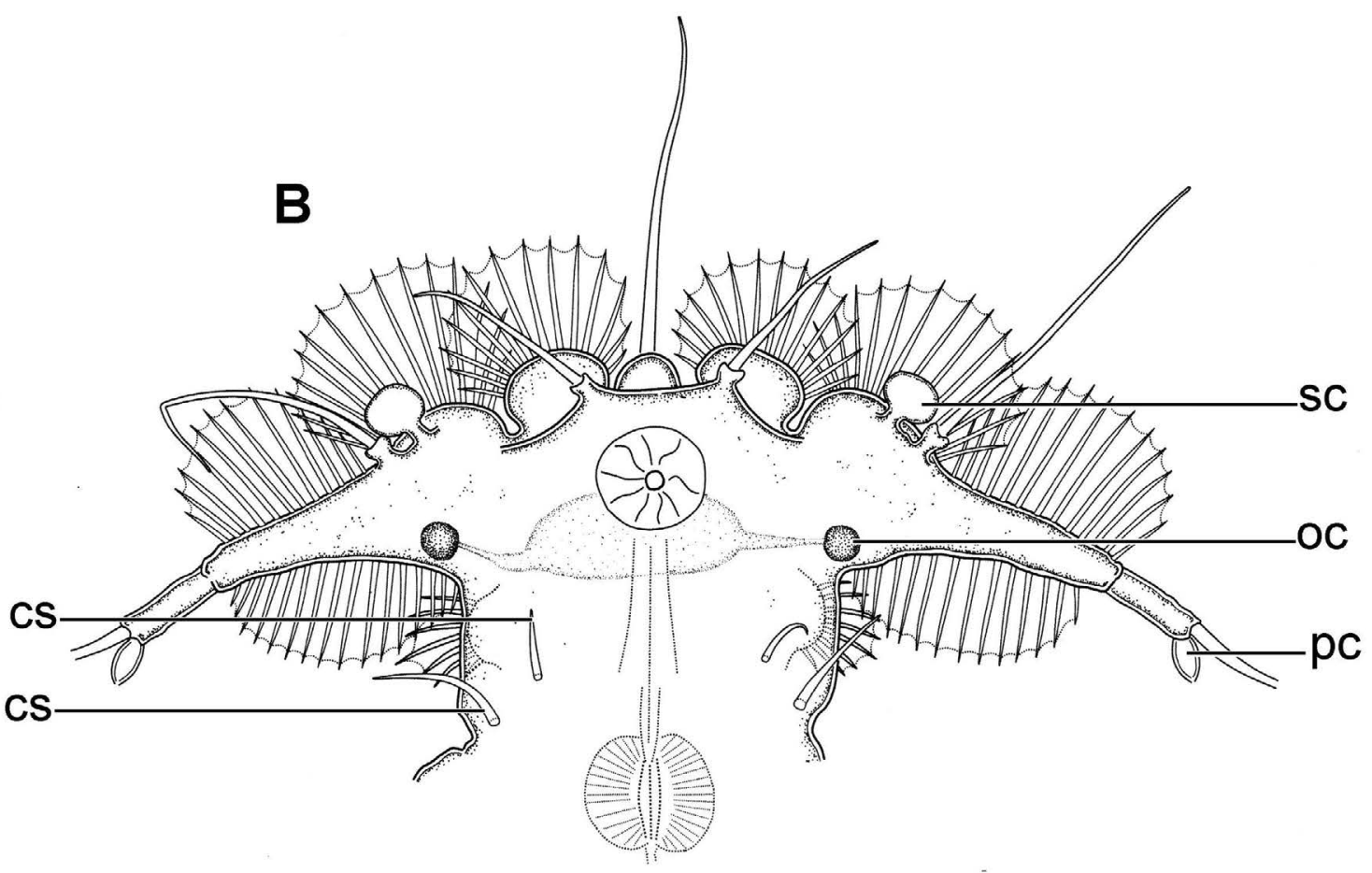

Fig. 3. Neostygarctus grossmeteori sp. nov., heads. A. Holotype, $q$ (SMF 51), dorsal view. B. Paratype, $q$ (SMF 52), ventral view. Scale bar $=50 \mu \mathrm{m}$. 

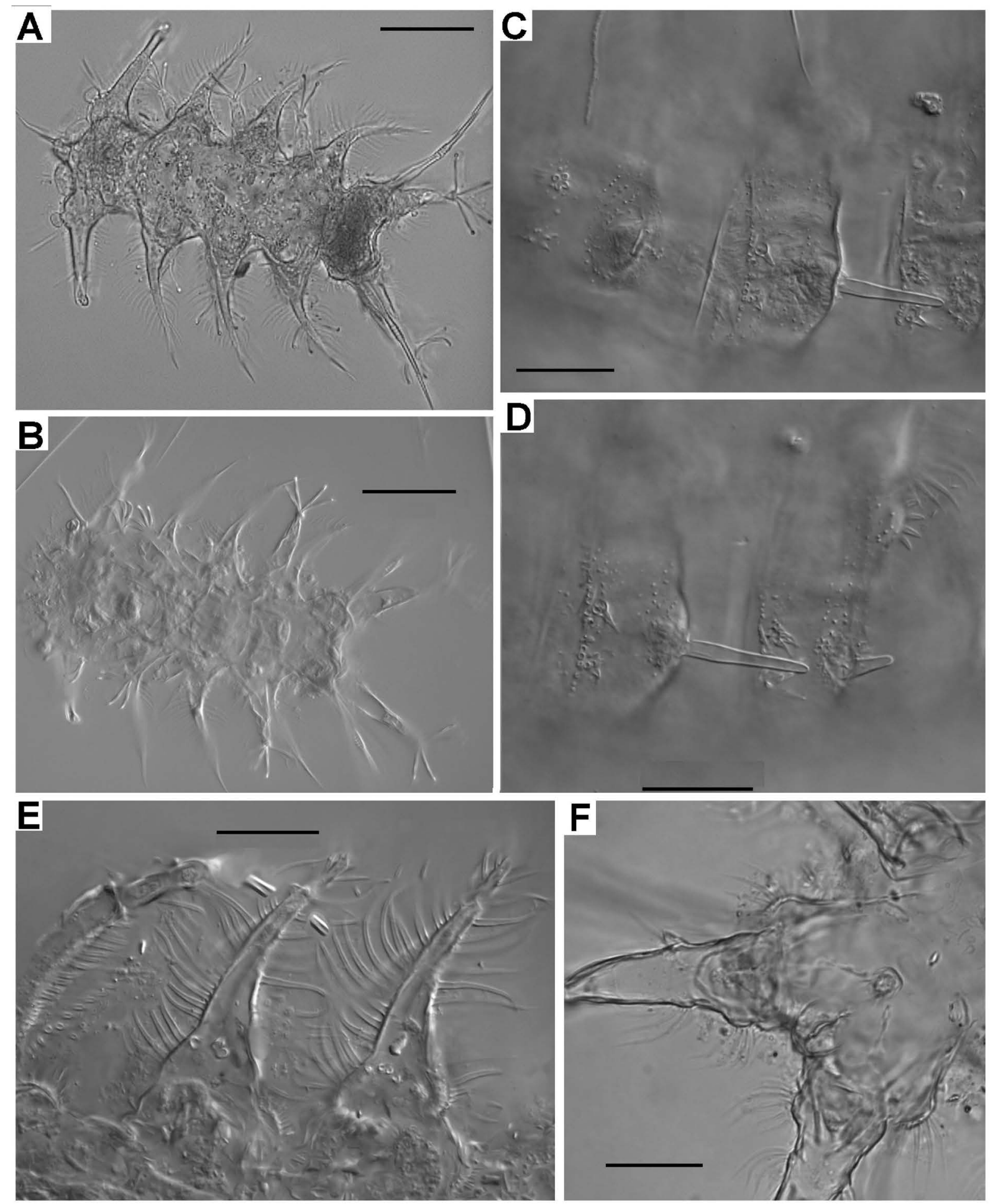

Fig. 4. Neostygarctus grossmeteori sp. nov., optical photopictures. A. Paratype, $q$ (SMF 54), entire body, dorsal view. B. Holotype, $q$ (SMF 51), entire body, ventral view. C-E. Paratype of obscure gender (SMF 59). C-D. Areas of dorsal surface of body with spines. E. Lateral body projections. F. Holotype, $q$ (SMF 51), posterior body with female gonopore and anus. Scale bars: A-B $=50 \mu \mathrm{m} ; \mathrm{C}-\mathrm{F}=20 \mu \mathrm{m}$. 


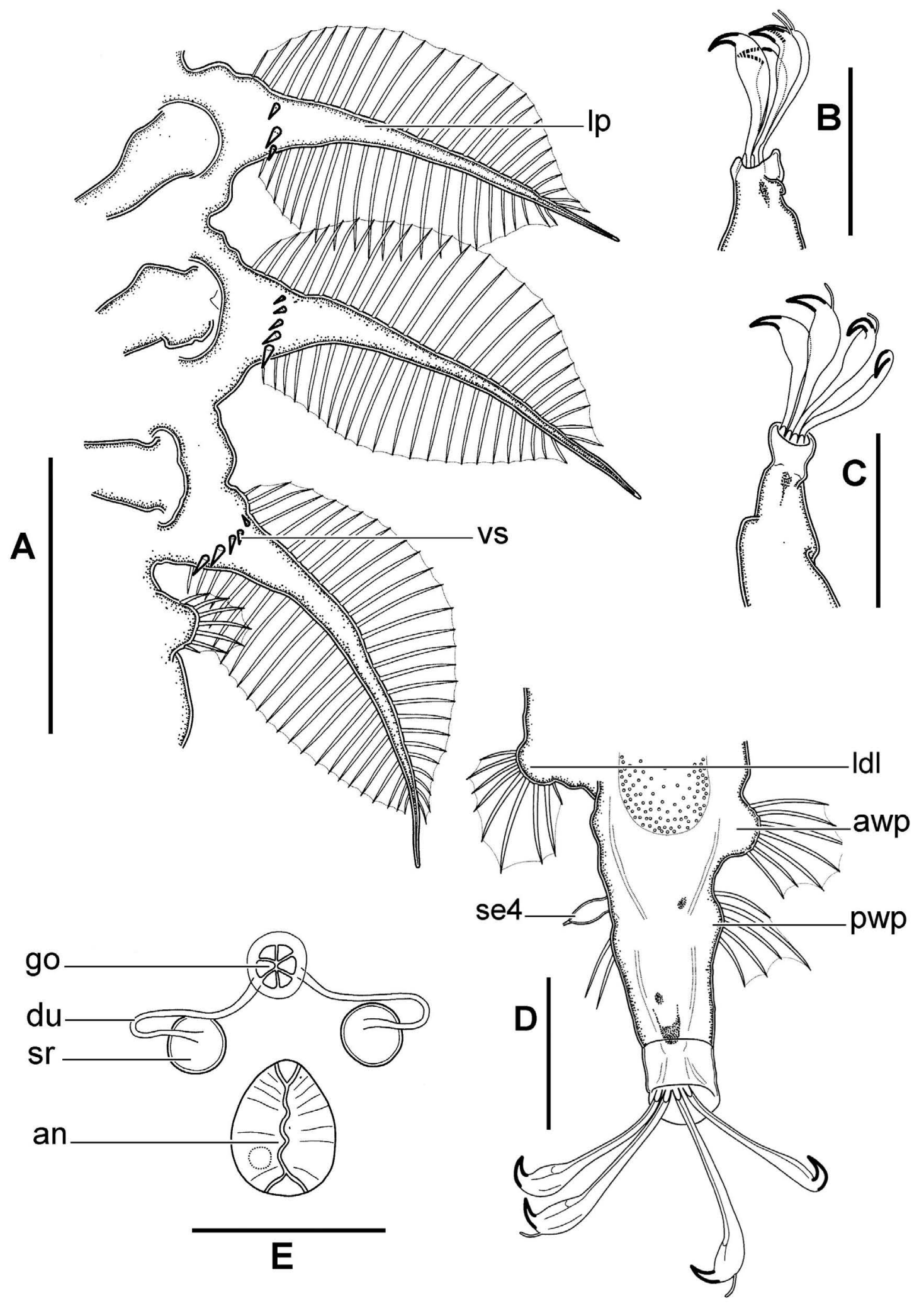

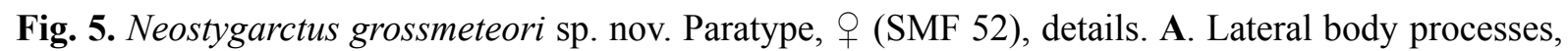
ventral view. B-D. Legs I (left and right) and IV. E. Genital area. Scale bars: A $=50 \mu \mathrm{m} ; \mathrm{B}-\mathrm{E}=20 \mu \mathrm{m}$. 

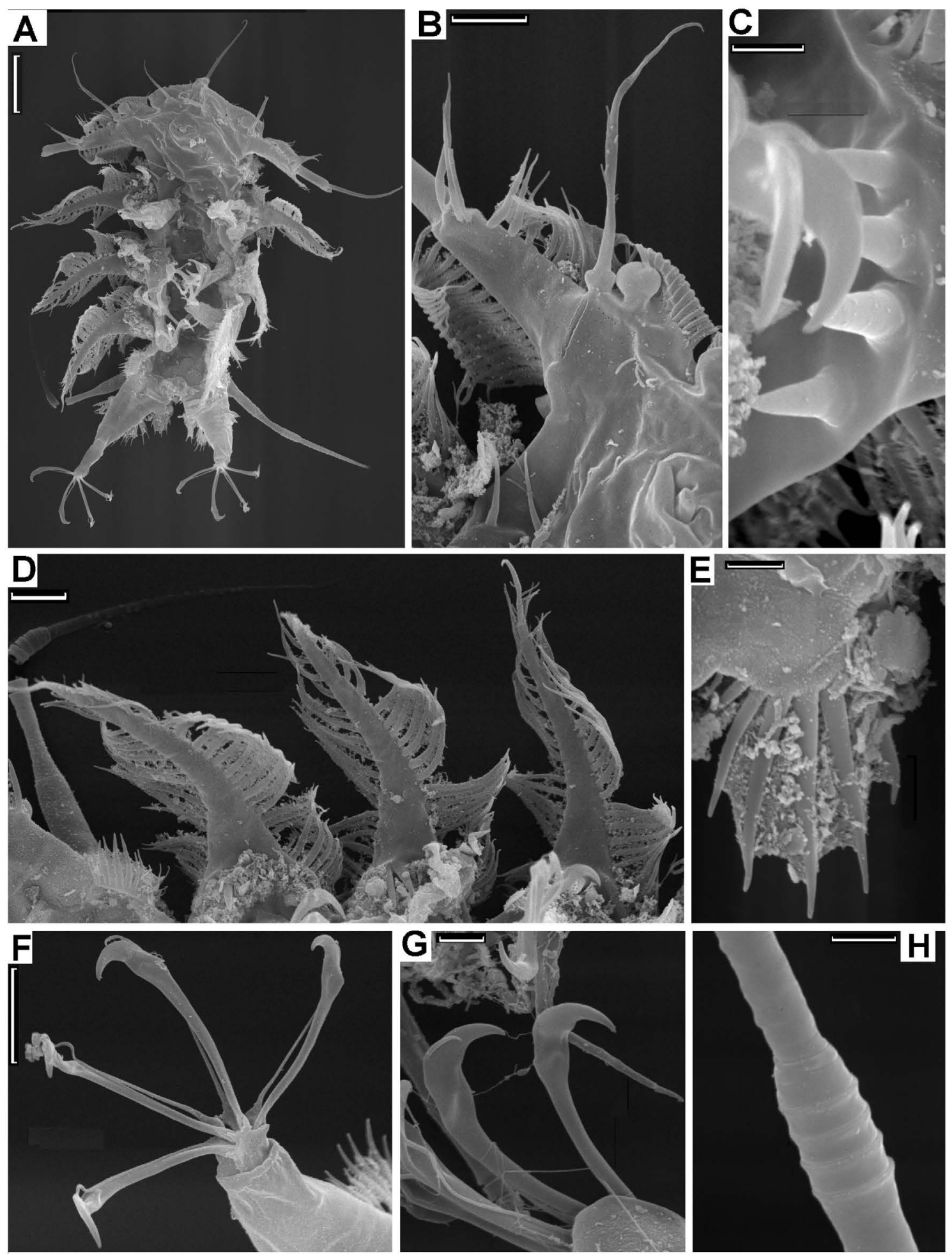

Fig. 6. Neostygarctus grossmeteori sp. nov., details, SEM. A. Female, entire body, ventral view. B. Right secondary clava and outer cirrus on the head, ventral view. C. Ventral conical spikes on the basal part of the lateral body process. D. Right lateral body processes. E. Lateral fan of spines with membrane on the posteriormost body segment. F. Toes with claws of the leg IV ventrally, dorsal tendon detached in some toes. G. Inner and outer claws, dorsal view. H. Accordion-like joint of the cirrus E. Scale bars: A = $30 \mu \mathrm{m} ; \mathrm{B}, \mathrm{D}, \mathrm{F}=10 \mu \mathrm{m} ; \mathrm{C}, \mathrm{E}, \mathrm{G}-\mathrm{H}=3 \mu \mathrm{m}$. 
In shape, they resemble cervical latero-dorsal lobes. Caudal segment bears another pair of caudal dorsal wart-like lobes (cdl) on posterior edge. All wart-like lobes armed with five to seven medium-sized spines.

SENSORY ORGANS. Long anterior flagellar median cirrus $(\mathrm{mc})$ rooted on prominent cirrophore hanging over anterior edge of head (Figs 2A-B, 3A-B). Internal cirri (ic) consist of short stub-shaped cirrophore and whip-like flagellum situated ventrally to anterior frontal lobes (Fig. 3A-B). External cirri (ec) situated ventrally to fronto-lateral lobes and also consist of short stub-shaped cirrophore and longer whip-like flagellum; similar in shape to internal cirri but a bit longer (Figs 2A-B, 3A-B, 6B). All cephalic cirri (flagellar parts) possess minute and sparse irregular lateral sprouts visible in SEM (Fig. 6B). External cirri located close to secondary clava just ventrally of fronto-lateral lobe edge. Globular secondary clava on short narrow stalk situated at inner position to external cirrus (Figs 3A-B, 6B). Cirrus A (lateral cirrus) and small primary clava rooted together on common cylindrical cirrophore (cc) which is continuation of lateral head lobe (Figs 3A-B, 6B); primary clava ovoid to lemon-shaped, with pointed terminal end. In some female and male specimens, paired ventral transversal slits (ts) observed just posterior to legs III (Fig. 2B); they are considered as possible sensory organs. No sensory organs present on legs I-III. Cirri $\mathrm{E}(\mathrm{cE})$ on caudal segment growing on body postero-laterally. Each cirrus E consists of long robust cirrophore without any discernible tubercles, cylindrical accordion-like thickening composed of three to five rings, and long whip-like flagellum (Figs 2A-B, 6H). Legs IV provided with latero-dorsal sense organs (se4) on external side of coxae. Sense organs small, ovoid, with tiny apical papillum (Figs 2A-B, $5 \mathrm{D})$.

LEGS I-IV. Rather long, consisting of long truncate conical coxa/femur, telescoping cylindrical tibia and palm-shaped (hand-shaped in Kristensen et al. 2015) tarsus with four equal digits. Border between coxa and femur indistinct. Legs I-III have neither sensory organs nor bristles. Legs IV provided with three groups of spines on coxa: (1) about ten short to medium-sized spines on anterior wart-like projection (awp) on internal side of coxa basally, (2) five to six medium-sized spines on posterior wart-like projection (pwp) on internal side of coxa right opposite to ovoid papilla, (3) about four medium-sized spines on external side of leg just ventrally to ovoid latero-dorsal sense organ (Fig. 5D).

DigiTs. Digits of legs IV bit longer than those of legs I-III. All digits of same leg about equal in length to one another. Digits long, slim and flat, with slight subterminal ventral bulge and terminal solid beak-like claws. Only internal claws provided with fine but distinct dorsal spine (accessory spine); external claws may bear very tiny appendage visible only in SEM and probably presenting vestigial spine. Peduncles (cuticular supports) not visible (Figs 5B-D, G, 6F-G).

Genito-Anal AREa. In females, gonopore (go) is six-lobed rosette-like structure within circle; two lateral sinuous seminal ducts (du) open posteriorly into spherical seminal receptacles (sr) (Fig. 5E). In males, transversally-oval gonopore situated more close to anal opening (Fig. 2B). Anal opening in both genders is longitudinal slit on anal plate posterior to gonopore.

INTERNAL ORGANS. Internal organs obscure in some specimens, possibly because of maceration. Pair of wide-set internal spheric ocelli (oc) at level of lateral lobes of head; ocelli pallid and indistinct in some specimens. Pharyngeal bulb obscure. Stylets not seen. Midgut and gonad not observed.

\section{Discussion}

Grimaldi de Zio et al. (1982) initially referred the newly established genus Neostygarctus to the family Stygarctidae Schulz, 1951. Kristensen \& Higgins (1984) transferred Neostygarctus to the Renaudarctidae Kristensen \& Higgins, 1984 particularly because Renaudarctus Kristensen \& Higgins, 1984 and Neostygarctus possess both toes with terminal claws and cuticular dorsal plates, and share some other common structural details. A few years later, the authors of the first species of Neostygarctus established 
a new monotypic family Neostygarctidae for only Neostygarctus considering its claws significantly different from those of other species of Renaudarctidae (Grimaldi de Zio et al. 1987). Moreover, Neostygarctus has been named a 'living fossil' and considered as starting point of two main diverging evolutionary lines of Heterotardigrada based on the structures of the toes (Grimaldi de Zio et al. 1987). The authors stressed plesiomorphic features such as strong middorsal spines, a prominent cirrophorus of the medial cirrus, the shape of the primary clava, and the shape of the cirrus E, whereas the lack of sense organs on the first three pairs of legs, some details of the buccal apparatus and the presence of eyes are considered as apomorphies. The justification of Neostygarctidae was further confirmed by Grimaldi de Zio et al. (1990). The monotypic status and basal position of the Neostygarctidae was also corroborated in a cladistic analysis of Bello \& Grimaldi de Zio (1998). In a further phylogenetic analysis based on a greater number of structural characters (Hansen et al. 2012), the hollow claws of Neostygarctus were interpreted as an autapomorphic feature and the genus Neostygarctus was re-interpreted as a sister group to other genera of Stygarctinae Schulz, 1951 and included in this subfamily. However, Kristensen et al. (2015) retained the monotypic family Neostygarctidae whilst admitting that the systematic position was still unsettled. Earlier assumptions on the arthrotardigrade phylogeny of Grimaldi de Zio et al. (1987) based on morphological characters are recently being reconsidered and partly denied by a molecular approach using nuclear 18S and 28S rRNA fragments by Fujimoto et al. (2017). Fontoura et al. (2017) accept the position of Neostygarctus within the subfamily Stygarctinae (family Stygarctidae).

The first species of Neostygarcus, N. acanthophorus, was described by Grimaldi de Zio et al. (1982) from the Bay of Taranto (South Italy) at a depth of $15 \mathrm{~m}$. A new description of N. acanthophorus made on specimens from around the Apennine Peninsula contains some more details on its external morphology (Grimaldi de Zio et al. 1990). Further findings of N. acanthophorus were made at various sites of the Mediterranean Sea (Grimaldi de Zio \& D'Addabo Gallo 2001) and the Maldivian Islands in the Indian Ocean (Gallo et al. 2007). The second species of Neostygarctus, N. lovedeluxe Fujimoto \& Miyazaki, 2013, was found in a submarine cave at Miyako Island (south Ryukyu Islands, Japan); the authors provided descriptions of adult specimens as well as of four- and two-clawed juveniles (Fujimoto \& Miyazaki 2013). The third species, N. oceanopolis Kristensen et al., 2015, was found at a depth of $206 \mathrm{~m}$ on the summit of the Condor Seamount located in the Azores, Northeast Atlantic (Kristensen et al. 2015). All the species of Neostygarctus are thus confined within sublittoral coarse sediments in oceans and seas of normal ocean salinity. Neostygarctus grossmeteori sp. nov. is so far the deepestdwelling species of the genus.

The differences between the species of Neostygarctus are summarized in Table 2. The new species is evidently most close to $N$. acanthophorus because of the number and position of middorsal spines but differs in having cervical spines and ventral spikes at the base of the lateral body processes. These two structures are mentioned neither in the original diagnosis of Grimaldi de Zio et al. (1982) nor in the redescription of Grimaldi de Zio et al. (1990) of $N$. acanthophorus. Neostygarctus grossmeteori sp. nov. differs from N. lovedeluxe Fujimoto \& Miyazaki, 2013 and N. oceanopolis Kristensen et al., 2015 even more clearly first of all by the number and position of the middorsal spines of the body, the presence of eyes as well as in other finer details such as claws.

The ventral cervical spines on the head and the ventral spikes on the lateral body processes were not mentioned for $N$. acanthophorus and N. lovedeluxe but they were indicated for N. oceanopolis. Since both cervical spines and ventral spikes are well visible structures, I assume that they were not missed in the descriptions of $N$. acanthophorus but actually absent or vestigial in that species and hence can be used as fair discriminative characters in the taxonomy of Neostygarctus.

On the other hand, transversal slits just posterior to the bases of leg IV are not unambiguously discernible in every specimen. These structures were not recorded in other species of Neostygarctus and their nature 
Table 2. Comparison of selected diagnostic characters between species of the genus Neostygarctus Grimaldi de Zio et al., 1982 based on literature data.

\begin{tabular}{|c|c|c|c|c|c|c|c|}
\hline Species & Reference & Locality & $\begin{array}{l}\text { Dorsal } \\
\text { structures }\end{array}$ & Eyes & $\begin{array}{l}\text { Cervical } \\
\text { spines }\end{array}$ & $\begin{array}{l}\text { Ventral spikes } \\
\text { on lateral body } \\
\text { processess } \\
\end{array}$ & Claws \\
\hline acanthophorus & $\begin{array}{l}\text { Grimaldi de } \\
\text { Zio et al. 1982, } \\
1990\end{array}$ & $\begin{array}{l}\text { Mediterranean, } \\
20-35 \mathrm{~m}, \\
\text { coarse sands }\end{array}$ & $\begin{array}{l}\text { Five middorsal } \\
\text { spines decreasing } \\
\text { in length rearwards }\end{array}$ & present & $\begin{array}{l}\text { not } \\
\text { mentioned }\end{array}$ & not mentioned & two internal with dorsal spine \\
\hline lovedeluxe & $\begin{array}{l}\text { Fujimoto \& } \\
\text { Miyazaki } 2013\end{array}$ & $\begin{array}{l}\text { Pacific, Ryukyu Arc, } \\
\text { Miyako Isl., } \\
\text { submarine cave, } \\
\text { pieces of broken } \\
\text { coral and sand }\end{array}$ & $\begin{array}{l}\text { Eight dorsal spines; } \\
\text { one medial on } \\
\text { cephalic and caudal } \\
\text { plates, two dorsal } \\
\text { spines on each of } \\
\text { three dorsal body } \\
\text { plates }\end{array}$ & absent & $\begin{array}{l}\text { not } \\
\text { mentioned }\end{array}$ & present & two internal with dorsal spine \\
\hline oceanopolis & $\begin{array}{l}\text { Kristensen } \\
\text { et al. } 2015\end{array}$ & $\begin{array}{l}\text { Atlantic, Azores, } \\
\text { summit of } \\
\text { Condor Seamount, } \\
206 \mathrm{~m} \text {, coarse } \\
\text { bioclastic sediment }\end{array}$ & $\begin{array}{l}\text { Seven middorsal } \\
\text { spines }\end{array}$ & absent & $\begin{array}{l}\text { one pair of } \\
\text { spines }\end{array}$ & $\begin{array}{l}\text { arranged in row along } \\
\text { the process }\end{array}$ & $\begin{array}{l}\text { all four claws with dorsal spine, } \\
\text { external claws with much } \\
\text { smaller spine }\end{array}$ \\
\hline $\begin{array}{l}\text { grossmeteori } \\
\text { sp. nov. }\end{array}$ & present paper & $\begin{array}{l}\text { Atlantic, Great } \\
\text { Meteor Seamount, } \\
270 \mathrm{~m} \text {, coarse } \\
\text { bioclastic sediment }\end{array}$ & $\begin{array}{l}\text { Five middorsal } \\
\text { spines decreasing } \\
\text { in length rearwards }\end{array}$ & present & $\begin{array}{l}\text { one or two } \\
\text { pairs }\end{array}$ & $\begin{array}{l}\text { arranged in row } \\
\text { athwart to the lateral } \\
\text { body process and } \\
\text { parallel to the body } \\
\text { axis }\end{array}$ & $\begin{array}{l}\text { two medial with dorsal spine, } \\
\text { external claws have vestigial } \\
\text { spine }\end{array}$ \\
\hline
\end{tabular}


is unknown. Minute sprouts sparsely distributed along the flagellar parts of the sensory organs of the head and visible only with SEM were not documented either for species of Neostygarctus. I consider the sprouts as pure cuticular structures and, because of the irregularity in number and position, they can be scarcely treated as sensory organs. The claws of the external digits of $N$. grossmeteori sp. nov. can be equipped with vestigial accessory spines revealed only in SEM, in addition to well developed spines on the internal claws; however, these vestigial spines are not discernible on each external claw. The external claws of $N$. oceanopolis also have very short accessory spines, also illustrated only by SEM pictures (Kristensen et al. 2015: fig. 7G). The accessory spines on the external claws are indicated neither for $N$. acanthophorus nor for $N$. lovedeluxe, possibly because SEM was not used for their observations. Thus, it is not definitely clear whether the external accessory spines are actually lacking in the latter two species or whether this character can work to differentiate the species of Neostygarctus. The presence or absence of ocelli or eye spots is often considered as an uncertain character because eyes can show an individual variability or disappear because storage of organisms in alcohol can dissolve the eye pigment. In the case of $N$. grossmeteori sp. nov., a preservation in alcohol is not documented, but is likely enough because ethanol is commonly used for a gradual transfer of organisms into glycerin. Specimens of $N$. grossmeteori sp. nov. have pale but discernible ocelli. Therefore, the presence or absence of eye spots can be established with a high probability even after preservation of specimens in alcohol. All these tentative discriminating characters should be evaluated in future studies.

\section{Acknowledgements}

The author thanks Dr. Kai Horst George for providing collections of tardigrades picked out from the samples of the meiofauna taken on the Great Meteor Seamount. Remarks and comments of two anonymous reviewers were very perfect and useful for improvement of the manuscript. The study was supported by the Russian Fund for Basic Researches (grant 15-04-02597) and the Russian Scientific Fund (grant 14-5000029).

\section{References}

Bartels P.J., Apodaca J.J., Mora C. \& Nelson D.R. 2016. A global biodiversity estimate of a poorly known taxon: Phylum Tardigrada. Zoological Journal of the Linnean Society 178 (4): 730-736. https://doi.org/10.1111/zoj.12441

Bello G. \& Grimaldi de Zio S. 1998. Phylogeny of the genera of the Stygarctidae and related families (Tardigrada: Heterotardigrada). Zoologischer Anzeiger 237 (2): 171-183.

Degma P., Bertolani R. \& Guidetti R. 2017. Actual checklist of Tardigrada species. Available from http://www.tardigrada.modena.unimo.it/miscellanea/Actual\%20checklist $\% 20$ of $\% 20$ Tardigrada.pdf, [accessed 8 Apr. 2017].

Fontoura P., Bartels P.J., Jørgensen A., Kristensen R.M. \& Hansen J.G. 2017. A dichotomous key to the genera of the marine heterotardigrades (Tardigrada). Zootaxa 4294 (1): 1-45.

https://doi.org/10.11646/zootaxa.4294.1.1

Fujimoto S. \& Miyazaki K. 2013. Neostygarctus lovedeluxe n. sp. from the Miyako Islands, Japan: the first record of Neostygarctidae (Heterotardigrada: Arthrotardigrada) from the Pacific. Zoologial Science 30: 414-419. https://doi.org/10.2108/zsj.30.414

Fujimoto S., Jørgensen A. \& Hansen J.G. 2017. A molecular approach to arthrotardigrade phylogeny (Heterotardigrada, Tardigrada). Zoologica Scripta 46 (4): 496-505. https://doi.org/10.1111/zsc.12221

Gad G. 2002. The relation between habitus and habitat structure as evidenced by a new species of Glochinema (Nematoda, Epsilonematidae) from the plateau of the Great Meteor Seamount. Hydrobiologia 474: 171-182. https://doi.org/10.1023/A:1016531720833 
Gad G. 2004a. The Loricifera fauna of the plateau of the Great Meteor Seamount. Archive of Fishery and Marine Research 51 (1-3): 9-29.

Gad G. 2004b. Diversity and assumed origin of the Epsilonematidae (Nematoda) of the plateau of the Great Meteor Seamount. Archive of Fishery and Marine Research 51 (1-3): 30-42.

Gad G. 2009. Colonisation and specialisation on seamounts, evidence from Draconematidae (Nematoda) of the Great Meteor Seamount. Marine Biodiversity 39: 57-69.

https://doi.org/10.1007/s12526-009-0007-6

Gallo M., D’Addabbo R., De Leonardis C., Sandulli R. \& Grimaldi de Zio S. 2007. The diversity of Indian Ocean Heterotardigrada. In: Pilato G. \& Rebecchi L. (eds) Proceedings of the Tenth International Symposium on Tardigrada, Journal of Limnology 66 (suppl.): 60-64.

https://doi.org/10.4081/jlimnol.2007.s1.60

George K.H. 2006. New Ancorabolinae Sars, 1909 (Copepoda, Harpacticoida, Ancorabolidae) of the Atlantic Ocean. Description of Pseudechinopsyllus sindemarkae gen. et sp. nov. and Dorsiceratus ursulae sp. nov. from the Great Meteor Seamount, and redescription of D. octocornis Drzycimski, 1967, and D. triarticulatus Coull, 1973 (part.). Meiofauna Marina 15: 123-156.

George K.H. 2013. Faunistic research on metazoan meiofauna from seamounts - a review. Meiofauna Marina 20: 1-32.

George K.H. \& Schminke H.K. 2002. Harpacticoida (Crustacea, Copepoda) of the Great Meteor Seamount, with first conclusions as to the origin of the plateau fauna. Marine Biology 141: 887-895. https://doi.org/10.1007/s00227-002-0878-6

Giere O. 2009. Meiobenthology: the microscopic motile fauna of aquatic sediments. $2^{\text {nd }}$ edition. SpringerVerlag, Berlin / Heidelberg.

Grimaldi de Zio S. \& D'Addabbo Gallo M. 2001. Further data on the Mediterranean Sea tardigrade fauna. Zoologischer Anzeiger 240: 345-360. https://doi.org/10.1078/0044-5231-00042

Grimaldi de Zio S., D’Addabbo Gallo M. \& Morone de Lucia M.R. 1982. Neostygarctus acanthophorus, n. gen., n. sp., nuovo Tardigrado marino del Mediterraneo. Cahiers de Biologie Marine 23: 319-323.

Grimaldi de Zio S., D’Addabbo Gallo M. \& Morone de Lucia M.R. 1987. Adaptive radiation and phylogenesis in marine Tardigrada and the establishment of Neostygarctidae, a new family of Heterotardigrada. Bollettino di Zoologia 54: 27-33.

Grimaldi de Zio S., D’Addabbo Gallo M., Morone de Lucia M.R. \& Troccoli A. 1990. New description of Neostygarctus acanthophorus (Tardigrada, Arthrotardigrada). Cahiers de Biologie Marine 31: 409416.

Hansen J.G. 2005. The ongoing investigation of the Faroe Bank tardigrade fauna. Frøđskapparit supplementum. Proceedings from the BIOFAR Symposium, Tórshavn, Faroe Islands, 24-26 April 2003, North-East Atlantic marine benthic organisms in the Faroes - taxonomy, distribution and ecology: 220 223.

Hansen J.G., D'Addabbo Gallo M.G. \& Grimaldi de Zio S. 2003. A comparison of morphological characters within the genus Rhomboarctus (Tardigrada: Heterotardigrada) with description of two new species. Zoologischer Anzeiger 242: 83-96. https://doi.org/10.1078/0044-5231-00089

Hansen J.G., Jørgensen A. \& Kristensen R.M. 2001. Preliminary studies of the tardigrade fauna of the Faroe Bank. Zoologischer Anzeiger 240: 385-393. https://doi.org/10.1078/0044-5231-00046

Hansen J.G., Kristensen R.M. \& Jørgensen A. 2012. The armoured marine tardigrades (Arthrotardigrada, Tardigrada). Scientia Danica. Series B, Biologica 2: 8-91. 
Jørgensen A. \& Kristensen R.M. 2001. A new tanarctid arthrotardigrade with buoyant bodies. Zoologischer Anzeiger 240: 425-439. https://doi.org/10.1078/0044-5231-00051

Kristensen R.M. \& Higgins R.P. 1984. A new family of Arthrotardigrada (Tardigrada: Heterotardigrada) from the Atlantic Coast of Florida, U.S.A. Transactions of the American Microscopical Society 103 (3): 295-311. https://doi.org/10.2307/3226191

Kristensen R.M., Sørensen M.V., Hansen J.G., Zeppilli D. 2015. A new species of Neostygarctus (Arthrotardigrada) from the Condor Seamount in the Azores, Northeast Atlantic. Marine Biodiversity 45 (3): 453-467. https://doi.org/10.1007/s12526-015-0323-y

Mohn C. 2010. Spotlight 5: Great Meteor Seamount. Oceanography 23 (1): 106-107. https://doi.org/10.5670/oceanog.2010.77

Renaud-Mornant J. 1988. Tardigrada. In: Higgins R.P. \& Thiel H. (eds) Introduction to the Study of Meiofauna: 357-361. Smithsonian Institution Press, Washigton, DC.

Manuscript received: 20 May 2018

Manuscript accepted: 30 October 2018

Published on: 27 November 2018

Topic editor: Rudy Jocqué

Desk editor: Pepe Fernández

Printed versions of all papers are also deposited in the libraries of the institutes that are members of the EJT consortium: Muséum national d'Histoire naturelle, Paris, France; Meise Botanic Garden, Belgium; Royal Museum for Central Africa, Tervuren, Belgium; Natural History Museum, London, United Kingdom; Royal Belgian Institute of Natural Sciences, Brussels, Belgium; Natural History Museum of Denmark, Copenhagen, Denmark; Naturalis Biodiversity Center, Leiden, the Netherlands; Museo Nacional de Ciencias Naturales-CSIC, Madrid, Spain; Real Jardín Botánico de Madrid CSIC, Spain; Zoological Research Museum Alexander Koenig, Bonn, Germany. 